leaflet of the MV annulus in the same manner as we did the anterior leaflet in this operation.

Our main approach to double valve endocarditis at present is AV homograft with MV repair or MV replacement with a bioprosthesis. There has always, however, been a challenge in IFB reconstruction. This new technique, despite being described here in a case of severe double valve endocarditis, is likely to serve in many other cases in which IFB reconstruction is required for reoperations or cases of extensive calcification at the base of the heart.

\section{References}

1. De Oliveira N, David T, Armstrong S, Ivanov J. Aortic and mitral valve replacement with reconstruction of the intervalvular fibrous body: an analysis of clinical outcomes. J Thorac Cardiovasc Surg. 2005;129:286-90.

2. Ali M, Iung B, Lansac E, Bruneval P, Acar C. Homograft replacement of the mitral valve: eight-year results. $J$ Thorac Cardiovasc Surg. 2004;128:529-34.

3. Obadia J, Hénaine R, Bergerot C, Ginon I, Nataf P, Chavanis N, et al. Monobloc aorto-mitral homograft or mechanical valve replacement: a new surgical option for extensive bivalvular endocarditis. J Thorac Cardiovasc Surg. 2006;131:243-5.

4. Chocron S, Buklas D, Taberlet C, Kaili D, Falcoz P, Etievent J. Monobloc aortomitral homograft: report of two cases. Ann Thorac Surg. 2007;84:e14-6.

5. Acar C. Monobloc or separate aortic and mitral homografts? J Thorac Cardiovasc Surg. 2006;132:442-3.

\title{
Complex diaphragm reconstruction using dermal collagen matrix after multivisceral resection of retroperitoneal sarcoma
}

\author{
Nicholas J. Harms, MD, ${ }^{a}$ Sima Naderi, MD, ${ }^{\mathrm{b}}$ Dariusz Borys, MD, ${ }^{\mathrm{c}}$ Richard J. Bold, MD, ${ }^{\mathrm{a}}$ and \\ Robert J. Canter, MD, ${ }^{\text {a }}$ Sacramento, Calif
}

Successful en bloc resection of retroperitoneal sarcomas may require contiguous organ resection, including the diaphragm. Tension-free, primary repair of the diaphragm is not always technically possible when a large defect is created. Standard reconstruction of complex diaphragmatic defects involves implantation of polytetrafluoroethylene mesh (Gore-Tex; WL Gore and Associates, Newark, Del). However, in the setting of visceral organ resection such as colon or pancreas, implantation of prosthetic mesh may be contraindicated because of concerns of postoperative infection. We report successful implantation of acellular dermal matrix (AlloDerm; LifeCell Corp, Branchburg, $\mathrm{NJ}$ ) to repair complex diaphragmatic defects in 2 patients after multivisceral resection of retroperitoneal sarcomas.

\section{CLINICAL SUMMARY}

A 72-year-old woman presented with an approximately $32-\mathrm{cm}$ recurrent left-sided retroperitoneal myxoid liposarcoma. Cross-sectional imaging suggested involvement of

\footnotetext{
From the Division of Surgical Oncology, ${ }^{\mathrm{a}}$ Department of Radiology, ${ }^{\mathrm{b}}$ and Department of Pathology and Laboratory Medicine, ${ }^{\mathrm{c}}$ University of California at Davis Cancer Center, Sacramento, Calif.

Disclosures: None.

Received for publication July 2, 2009; revisions received July 2, 2009; accepted for publication July 9, 2009; available ahead of print Oct 26, 2009.

Address for reprints: Robert J. Canter, MD, Division of Surgical Oncology, Suite 3010, UC Davis Cancer Center, 4501 X Street, Sacramento, CA 95817 (E-mail: Robert.canter@ucdmc.ucdavis.edu).

J Thorac Cardiovasc Surg 2010;139:1081-3

$0022-5223 / \$ 36.00$

Copyright (C) 2010 by The American Association for Thoracic Surgery

doi:10.1016/j.jtcvs.2009.07.077
}

the distal pancreas, spleen, descending colon, and left hemidiaphragm (Figure 1, A). Staging studies were consistent with localized disease.

Resection of this large, recurrent sarcoma was performed with concurrent left hemicolectomy, distal pancreatectomy, splenectomy, partial psoas muscle, and left hemidiaphragm resection. An approximate $120-\mathrm{cm}^{2}$ defect was created in the diaphragm, extending from the posterior portion of the central tendon to the posterolateral rib cage. Given the size of the defect, a tension-free, primary repair was not technically possible. In the setting of concomitant intestinal and pancreatic resections, implantation of prosthetic mesh was thought to be contraindicated because of the risk of mesh contamination.

Diaphragmatic reconstruction was accomplished with AlloDerm using interrupted 0-0 Prolene sutures to anchor the graft to the rib periosteum posterolaterally, to the left crus medially, and to the central tendon anteriorly (Figure 2).

A 68 -year-old man presented with a $12-\mathrm{cm}$ left retroperitoneal mass that proved to be a renal angiosarcoma (Figure 1, $B)$. At operation, the tumor was found to involve the tail of the pancreas, the spleen, and the diaphragm, necessitating a multivisceral en bloc resection. Resection of a portion of the left hemidiaphragm created an approximately $45-\mathrm{cm}^{2}$ triangular defect, extending laterally and anteriorly from the left crus. Although a portion of the defect was repaired primarily, a complete, tension-free repair was not technically possible. A 3- $\times 7$-cm piece of AlloDerm was used to repair the posterior-lateral defect using interrupted 0-0 Prolene sutures. 

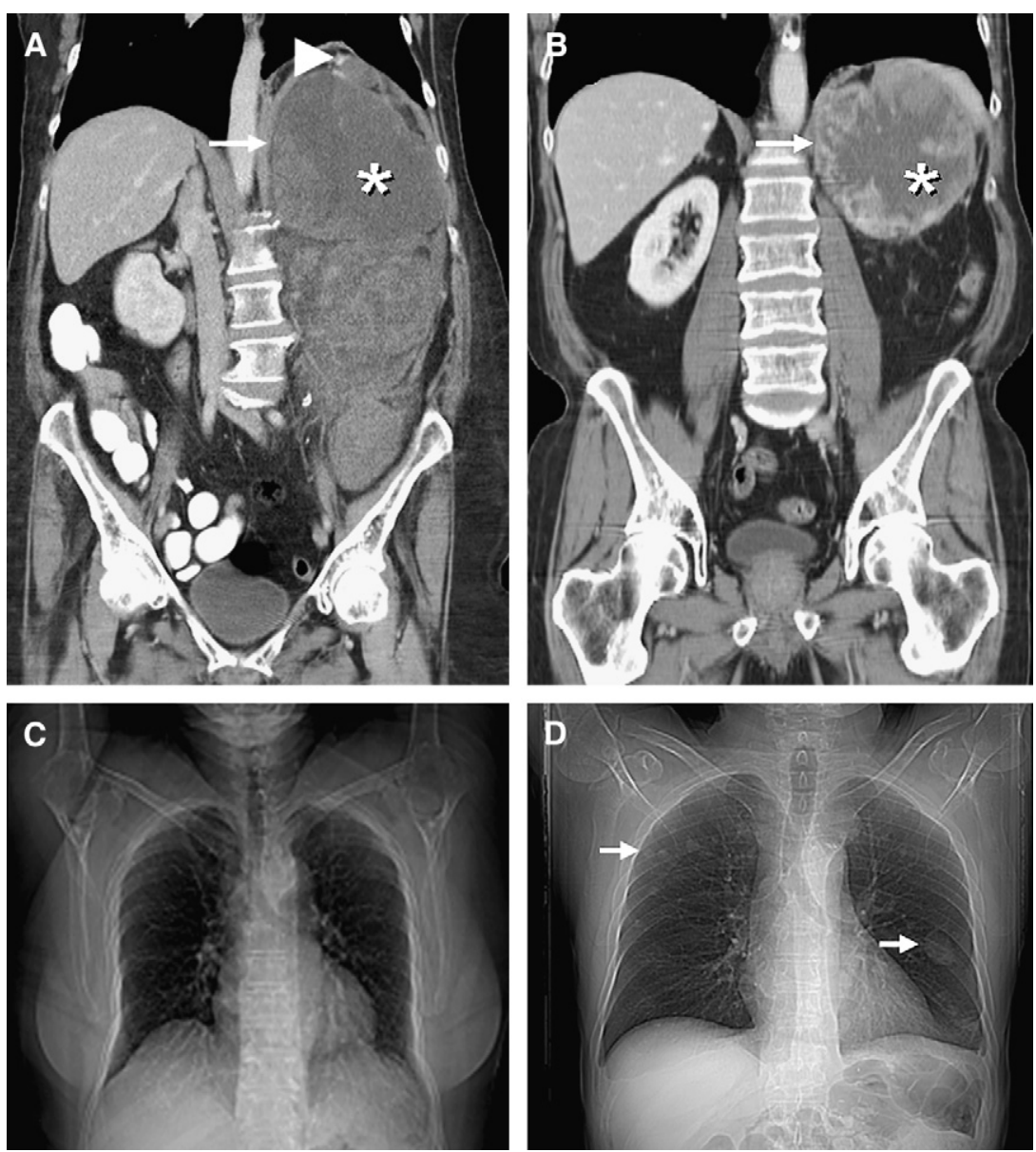

FIGURE 1. A, Preoperative computed tomography (CT) scan, coronal reconstruction, demonstrating recurrent left retroperitoneal sarcoma extending from hemidiaphragm to pelvis. Tumor (*), area suspicious for diaphragm involvement (arrow), and possible herniation of tumor (arrowhead) through foramen of Bochdalek hernia. B, Preoperative CT scan, coronal reconstruction, demonstrating left retroperitoneal sarcoma. Tumor $\left({ }^{*}\right)$ and area suspicious for diaphragm involvement (arrow). C, Scout film from CT 6 months after resection demonstrating intact left hemidiaphragm. D, Scout film from CT scan 6 months after resection showing intact left hemidiaphragm. Bilateral lung metastases are present (arrows).

The patients were managed postoperatively with thoracostomy tube removal within 48 hours. After an uneventful early postoperative course, both patients re-presented with nausea, left upper quadrant pain, and mild dyspnea. Crosssectional imaging revealed fluid collections that were drained percutaneously. In the first patient, a subphrenic abscess was diagnosed, whereas in the second patient, a sterile pleural fluid collection was drained. Each patient responded to conservative management with resolution of symptoms and clearance of postoperative fluid collections.

Six months postoperatively, radiographic evaluation showed an intact left hemidiaphragm repair in both patients (Figure 1, C, D), although the second patient had pulmonary metastases (Figure 1,D).

\section{DISCUSSION}

Visceral, pulmonary, urologic, or gynecologic cancers may require en bloc resection of a portion of the diaphragm. Although standard reconstruction of complex diaphragmatic defects involves implantation of prosthetic mesh, this may be contraindicated in cases with bacterial contamination. ${ }^{1}$ Diaphragmatic reconstruction with autologous tissue muscle flaps has been successfully performed in cases involving significant bacterial contamination, but this approach is complex and introduces potential morbidities related to flap necrosis and donor-site complications. ${ }^{2}$

Biological grafts have gained acceptance for soft-tissue reconstruction, particularly when there is concern for potential bacterial contamination. Notable benefits include (1) their technical ease of use because they feel and suture much like native tissue; (2) their long-term vascularization and incorporation into native tissue; and (3) their permeability to the immunosurveillance host cells, which may reduce the risk of graft infection. ${ }^{3}$ The largest experience has been reported for abdominal wall reconstruction in the setting of complex abdominal wall hernias or enterocutaneous fistula. ${ }^{3}$ Additional reported uses include parastomal hernia repair, crural reinforcement after paraesophageal hernia repair, ${ }^{4}$ 


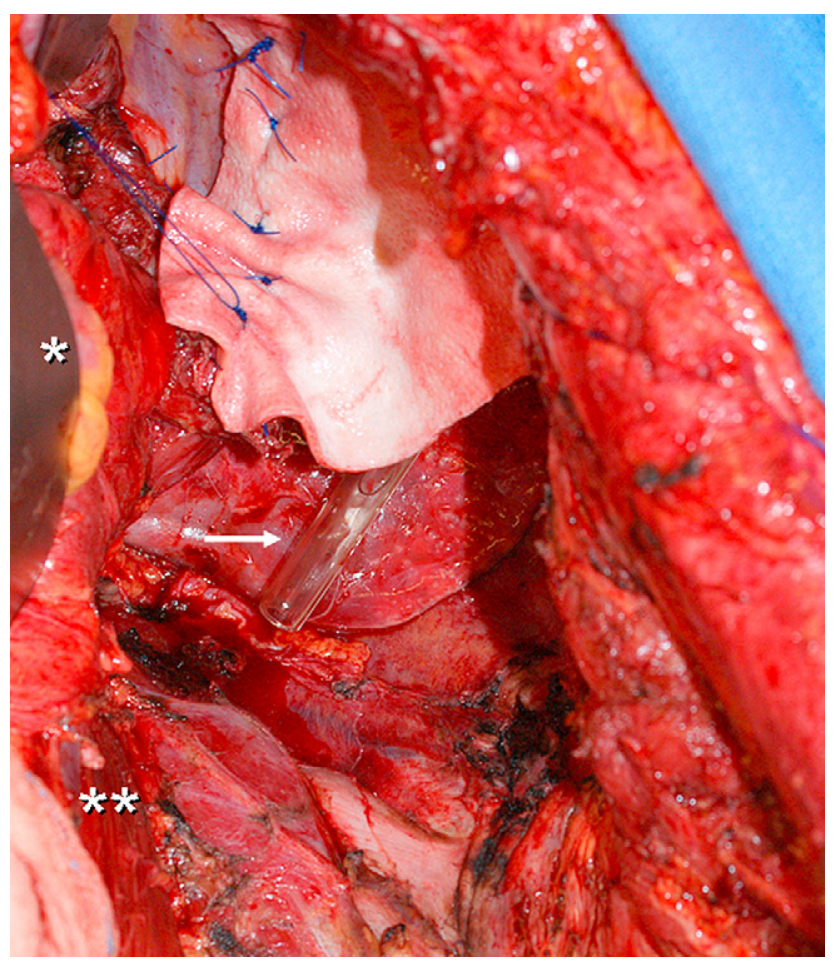

FIGURE 2. Intraoperative photograph of diaphragm reconstruction in the first patient using AlloDerm (LifeCell Corp, Branchburg, NJ). Retractor (*) on duodenal-jejunal flexure; left psoas muscle $(* *)$. Lung parenchyma and pleural thoracostomy tube before completion of diaphragm repair (arrow).

and repair of tracheoesophageal fistula. ${ }^{5}$ To our knowledge, this is the first report of the successful use of AlloDerm for diaphragm reconstruction after multivisceral retroperitoneal sarcoma resection.

\section{CONCLUSIONS}

The patients in this report have been followed for more than 6 months postoperatively, and they continue to do well with the structural integrity of their diaphragms confirmed radiographically. Although postoperative fluid collections (a subphrenic abscess and a sterile pleural fluid collection) developed in the patients, these collections were managed conservatively in both cases with good outcome and the AlloDerm was preserved. In future cases, consideration of more prolonged tube thoracostomy drainage may help avoid subsequent reaccumulation of fluid. AlloDerm seems to be a safe technique for complex diaphragmatic reconstruction after multivisceral resection of retroperitoneal sarcoma.

\section{References}

1. Fuks D, Dumont F, Berna P, et al. Case report-complex management of a postoperative bronchogastric fistula after laparoscopic sleeve gastrectomy. Obes Surg. 2009;19:261-4.

2. McConkey MO, Temple CL, McFadden S, Temple WJ. Autologous diaphragm reconstruction with the pedicled latissimus dorsi flap. J Surg Oncol. 2006;94: 248-51.

3. Hiles M, Record Ritchie RD, Altizer AM. Are biologic grafts effective for hernia repair?: a systematic review of the literature. Surg Innov. 2009;16:26-37.

4. Lee YK, James E, Bochkarev V, et al. Long-term outcome of cruroplasty reinforcement with human acellular dermal matrix in large paraesophageal hiatal hernia. J Gastrointest Surg. 2008;12:811-5.

5. Su JW, Mason DP, Murthy SC, Rice TW. Closure of a large tracheoesophageal fistula using AlloDerm. J Thorac Cardiovasc Surg. 2008;135:706-7.

\title{
Rib osteotomy and fixation: Enabling technique for better minithoracotomy exposure in cardiac and thoracic procedures
}

\author{
Jai Raman, MD, FRACS, PhD, David Onsager, MD, and David Straus, MD, Chicago, Ill
}

Chronic postthoracotomy pain is a common complication of thoracotomy, occurring in approximately $50 \%$ of patients. ${ }^{1}$ Severe and disabling pain affects $5 \%$ of patients after

From the University of Chicago Medical Center, Chicago, Ill.

Disclosures: J.S.R. reports grant support from Biomet Microfixation.

Received for publication July 16, 2009; revisions received Aug 21, 2009; accepted for publication Sept 2, 2009; available ahead of print Nov 12, 2009.

Address for reprints: Jaishankar Raman, MD, FRACS, PhD, Associate Professor of Surgery, Director of Adult Cardiac Surgery, University of Chicago, MC 5040,

5841 South Maryland Ave, Chicago, IL 60637 (E-mail: jraman1@uchicago.edu). J Thorac Cardiovasc Surg 2010;139:1083-5

$0022-5223 / \$ 36.00$

Copyright (C) 2010 by The American Association for Thoracic Surgery

doi:10.1016/j.jtcvs.2009.09.014 thoracotomy. Chronic postthoracotomy pain persists for greater than 2 months after the surgical procedure and is characterized by allodynic responses to mechanical and cold stimulation. To date, there is no objective evidence that postthoracotomy pain diminishes over time, despite popular opinion. ${ }^{2}$ Chronic postthoracotomy pain is thought to result from intercostal nerve damage sustained during rib retraction or reduction. ${ }^{2}$ A variety of surgical modifications have been developed to overcome this painful complication, ranging from local rib resection to muscle-sparing thoracotomies and mobilization of the intercostal nerve. Here we describe a thoracotomy technique that minimizes intraoperative trauma to the intercostal neurovascular 